\title{
Sterilisation of those with intellectual disability: evolution from non-consensual interventions to strict safeguards
}

\section{Sam Rowlands}

Faculty of Health \& Social Sciences, Bournemouth University, Bournemouth, United Kingdom of Great Britain and Northern Ireland

ORCID ID: http://orcid.org/0000-0001-5940-9079

\section{Jean-Jacques Amy}

Faculty of Medicine \& Pharmacy, Vrije Universiteit Brussel, Brussels, Belgium

Correspondence to:

Sam Rowlands, Centre of Postgraduate Medical Research \& Education, Bournemouth University, Royal London House, Christchurch Road, Bournemouth, BH1 3LT, UK Email: srowlands@bournemouth.ac.uk 


\section{Abstract}

Non-consensual sterilisation is one of the characteristic historical abuses that took place mainly in the first half of the $20^{\text {th }}$-century. People with intellectual disability were a prime target as part of the ideology of negative eugenics. In certain jurisdictions, laws were in force for several decades that permitted sterilisation without the need for consent, or with consent from third parties. The long-term adverse effects on those sterilised against their will have only more recently been recognised. In the latter half of the $20^{\text {th }}$-century, human rights treaties were introduced and developed; they have in the main curbed sterilisation abuses. Courts have developed more stringent criteria for making decisions on applications for sterilisation and nowadays there are mostly adequate safeguards in place to protect those with intellectual disability from non-consensual sterilisation, except when it is overwhelmingly the right decision for an individual, taking into account all the medical and social factors of a particular case.

\section{Word count}

6,795 words 


\section{Keywords}

consent, forced, human rights, intellectual disability, sterilisation 


\section{Introduction}

The origins of sterilisation of those with intellectual disability (ID) can be traced back to the very end of the $19^{\text {th }}$-century, prompted by the eugenics movement. Sterilisation procedures took place with alarming frequency during the first four decades of the $20^{\text {th }}$-century (Park and Radford, 1998). Although a modern human rights approach to sterilisation of those with ID is now generally well-established, there are currently a few countries in which nonconsensual sterilisation still takes place, for example those with repressive governments (North Korea and Uzbekistan) and those with a legacy of population policies consisting mainly of birth rate reducing measures (China and India).

The so-called feebleminded were a prime target of the eugenics movement (SSHRCC, 2017). They were thought to be a "danger to the community" (Editorial, 1910) and a "menace to society" (Queen's Bench of Alberta, 1996); it was generally felt that they should be segregated and prevented from reproducing (so-called negative eugenics; positive eugenics is encouraging procreation among 'fit' people). Eugenicists strongly believed that the feebleminded should be sterilised in the cause of 'human betterment'. Based on the assumption (generally false as it turned out) that ID was inherited, unchecked reproduction by those with ID would reduce overall intelligence in the population. Also, there was the belief that most women with ID were unfit for parenthood (Stefánsdóttir and Hreinsdóttir, 2013).

Laws were passed in countries (or certain States/Provinces/Cantons within countries with federal systems) in which pressure from the eugenics movement persuaded the politicians 
to vote for compulsory sterilisation; this happened in relatively few countries. With the backing of these laws and in an era before the ethics of consent and reproductive rights had been developed, what are nowadays considered to be abuses became widespread.

One of the most influential early court cases was that of Buck v Bell in 1927. The judge made what were in those days matter-of-fact eugenic, and nowadays would be considered at the very least discriminatory, comments about the Buck family. Justice Oliver Wendell Holmes stated that "society can prevent those who are manifestly unfit from continuing their kind ... three generations of imbeciles are enough". Following this US Supreme Court case, nonconsensual sterilisations were legitimated in the USA.

This article examines the circumstances and extent of these historical abuses and how, later on, they were exposed. The article goes on to explore how individuals with ID were affected by the sterilisation, the reparations that were eventually forthcoming in some countries, the development of policies to prevent such abuses and how the regulation of applications for sterilisation in those without capacity should look in the modern world.

The authors conducted a literature search on all material freely available on the subject, without resorting to the examination of original documents. These sources included journals in various disciplines, books, theses, government publications, publications by nongovernmental organisations, articles in the lay press and information from reliable internet sources. 


\section{Background}

\section{Intellectual disability}

The history of intellectual disability is full of derogatory terminology. However, care is needed not to judge what was official policy many years ago by today's standards of political correctness. Over the years in England and Wales there were a series of Madhouses Acts and Lunacy Acts which governed detention of those considered to have mental disorders in 'asylums'. The Idiots Act 1886 made the distinction between 'idiots' and 'imbeciles' (Social History of Learning Disability Research Group, 2012). The Lunacy Act 1890 enabled the creation of asylums dedicated to 'idiots'. The Mental Deficiency Act 1913 defined feebleminded people as those requiring care, supervision or control to protect themselves and distinguished them from the severer forms of 'defectiveness', namely idiots (most severe) and imbeciles (intermediate). Lunacy and Mental Deficiency Acts were repealed by the Mental Health Act 1959; this latter Act abolished the term 'moral imbecile' which was used to describe those considered to have normal intellect but a deficiency in morality.

The US psychologist Henry Goddard who pioneered intelligence quotient (IQ) testing in the USA (Benjamin, 2009), coined the term 'moron' for those with an IQ of $51-70$, higher than 'idiots' and 'imbeciles'. Goddard originally (in 1912) stated that the feebleminded "multiplied at twice the rate of the general population"; later in his life he admitted that much of his research on eugenics had been incorrect. His initial view of differential fecundity was shared by many in the eugenics movements in the USA and UK. Many countries sterilised men and women under the guise of feeblemindedness, it being a conveniently vague grouping to put people into who did not come under more precise diagnostic categories such as 
schizophrenia. Some of those categorised as feebleminded were in fact merely lacking in education. It is true, however, that there was little scientific understanding of ID until more recent years.

Evidence about the extent of sterilisation of those with ID is patchy. Countries without literature on the subject are not necessarily uninvolved. Countries with extensive documentation tend to be those with motivated scientists and historians. In some instances, the intense scrutiny of the cases appears to be related to a process of atonement. Certain human rights cases have been brought many years after the event; some of these have failed due to procedural difficulties.

\section{Legal context of involuntary sterilisation and involvement of professionals}

There is virtually no correlation between passing laws allowing involuntary sterilisation and the degree to which such sterilisation was practised. Involuntary sterilisation has been carried out, to a variable extent, in countries with no such law and in some countries with a law very little involuntary sterilisation took place. See, for example, the case history below about Ingrid Van Butsel who was sterilised in Belgium, a country that has never had a law permitting involuntary sterilisation.

Physicians have figured prominently in the history of non-consensual sterilisation. In the USA for example, starting in 1894, Hoyt Pilcher began authorising the castration of boys and sterilisation of girls in the Kansas State Asylum for Idiotic and Imbecile Youth - later called the Winfield State Home for the Feeble-Minded (Trombley, 1988). Other notable Superintendents of Institutions were William Partlow in Alabama, F O Butler of California, 
Benjamin Whitten of South Carolina, Albert Priddy and his successor John Bell of Virginia (of Buck $v$ Bell notoriety) and Albert Wilmarth of Wisconsin. It is worthy of note that none of the numerous US institutions that are still in existence and used for residential care for those with ID mention the history of sterilisation abuse on their websites (Kaelber, 2011).

It is impossible to give accurate estimates of the numbers of people with ID who were sterilised under the laws mentioned above; the proportions of the totals varied between jurisdictions and over time. The ratio of male to female sterilisations varied too, but generally women were targeted more than men. Altogether, more than 60,000 eugenic sterilisations took place in the USA (Kaelber, 2011) and more than 3,000 procedures in Canada (SSHRCC, 2017). In Nazi Germany, as many as 400,000 individuals were sterilised (Proctor, 1988). In Sweden there were more than 30,000 involuntary sterilisations - half the total sterilisations (Drouard, 1999); in Denmark about 11,000 sterilisations (Jütte, 2008).

\section{Double injury}

Involuntary sterilisation is both an act of physical and moral injury (Braun et al., 2014). It not only destroys a person's reproductive capability but also places a value judgement on the person, a statement of inferior worth. Policies that promote or condone involuntary sterilisation are therefore inherently stigmatising and degrading as well as violating people's physical integrity.

\section{Epidemiology}

Very little epidemiological data on this subject exist to indicate whether laws and policies are adhered to or people with intellectual disorders are discriminated against. One exception is 
Belgian research from the early 2000s. A population-based study showed a three-fold higher prevalence of sterilisation amongst women with ID than in the general population (Servais et al., 2004). It would be expected that with greater availability of reversible alternatives, sterilisation would nowadays become less common in women with ID, as it is in the general population.

\section{Consent and capacity}

The issue of consent has a fundamental bearing on how people with ID are treated. Thinking on consent has evolved considerably in more recent decades. Some individuals may not have the mental capacity to make a decision about sterilisation. However, modern-day thinking is that everyone should be presumed to have this capacity unless it can be shown by thorough assessment that it is not reached (Laurie et al., 2016). The other basic principle is that capacity may possibly be reached in the future, either given time or given support, assistance and training. For adults who clearly lack capacity at a particular time, no-one else can give valid consent on their behalf; only a Court can authorise an operation with such significance. In order for consent to be valid, not only must individuals have capacity but they must receive adequate information about the procedure and must be free from coercion or undue influence. The historical, draconian sterilisation laws either took away any right to give consent or allowed coercive practices. Some laws directed that people with ID appear before a committee with the power to make decisions; some of these had an appeals process, but often the success rate of the appeals was very low. Very often vulnerable individuals were subjected to inhumane procedures that ignored their bodily autonomy. Sometimes there were coercive incentives associated with the consent process. 
It is important to take into account the fact that those with ID are susceptible to acquiescence to a proposed course of action (Howard and Hendy, 2004). This is due both to difficulties with cognition and to their relative powerlessness in society.

The social model of disability highlights how society disables people through discriminatory attitudes and oppressive ideas, rather than conceptualising individual bodies/minds as having deviated from the norm. People's inability to participate in society is less determined by their own particular abilities than by physical, attitudinal, economic and social barriers that could, at least in theory, be removed or modified (Watson, 2016). Modern thinking is that instead of using a cognitive capacity model countries should be moving towards a 'will and preference' model (Parker, 2013). Individuals facing the decision contribute by expressing their will and preference, using a range of informal communication methods such as body language, facial expression, gesture, and physiological reactions (e.g., altered breathing patterns). Supporters contribute to the process by responding to these expressions of will and preference, through acknowledging (as opposed to ignoring), interpreting and acting on this expression (Watson, 2016).

\section{Sterilisation of the institutionalised}

Building institutions was society's solution to coping with substantial numbers of people with ID; segregation was seen as containing the 'problem'. The institutionalised were those primarily targeted in sterilisation efforts in the 1930s and 1940s, predominantly in North America, Western Europe and the Nordic countries. It is thought that more individuals with 
ID were sterilised in the Sonoma State Home, California, than in any other institution in the world up to 1942 (Kaelber, 2011). The institution at which most of the sterilisations in Virginia, USA, were done was in Lynchburg - the same place Carrie Buck and her sister Doris were sterilised (Trombley, 1988) and in which forced sterilisations continued up until 1973. Twenty-eight former Lynchburg residents gave detailed statements to the Richmond branch of the American Civil Liberties Union in connection with a class-action lawsuit in 1985. Most of them were admitted at ages 12 to 16 and then were put to work, not receiving any significant education. They alleged that sterilisation was only one of the dehumanising practices they were subjected to. They described sexual abuse, medical experimentation and other activities reminiscent of the Nazi régime (Trombley, 1988). Perhaps one of the most cruel was being forced to assist in the operating theatre.

Sterilisations were forced by institutions, not just using coercion with threats. If sterilisation was not accepted, the precondition would not happen. There are examples of sterilisation as a precondition for admission to the institution (see the case history on Leilani Muir), as a precondition for discharge into the community (Brady, 2001; Carey, 1998; Lynöe, 2007; Park and Radford, 1998; Ramsay, 2000; Stefánsdóttir, 2014; Trombley, 1988) and many in which their residential status made them a 'soft target'. Sterilisation as a precondition for discharge is related by Swedish interviewees (Anonymous, 2000). Yngve was subjected to a vasectomy at the age of 16 while a resident at an institution in Uppsala in 1943. Elisabeth was sterilised at the age of 17 as a condition for discharge from Sjötorp vocational school in 1949.

[Insert Box about Leilani Muir about here] 


\section{Reasons for sterilisation}

Extracts from the archives of the Alberta Eugenics Board spanning a 43-year period from 1929 to 1972 make sobering, if not chilling, reading. In the records of those who went forward with the Board's approval for sterilisation, for example, were those who were "incapable of intelligent parenthood", had "more than average interest in the opposite sex", "gave birth to an illegitimate child" and suffered "spousal abandonment" (Park and Radford, 1998). Some children who came across as perfectly normal in their medical assessment were sterilised on account of a poor home environment.

The reasons given for admission to institutions in Virginia were more social than medical. The diagnosis of 'mental retardation' was used in a liberal manner. A person from a deprived, rural area who exhibited behaviour which was not the norm for white, middleclass America was often diagnosed as having 'cultural, familial mental retardation' (Trombley, 1988).

[Insert Box about Ingrid Van Butsel about here]

Flimsy reasons for classifying people as having ID and for assessing them as having serious adverse social circumstances were commonplace in several countries. Those living in poverty (see case history of Ingrid Van Butsel) and those with educational problems were subjected to sterilisation. Assessments made were often inadequate or slapdash. Some individuals were classified as having ID without IQ testing. Some with treatable physical problems were classed as having educational difficulties (see case history of Maria Nordin). 
[Insert Box about Maria Nordin about here]

\section{Sterilisation by deception}

There are examples in which social workers or healthcare professionals deliberately lied to people with ID, a common deceit being that an appendicectomy was needed. At the age of 14, Ebba Hreinsdóttir was taken to hospital by her family in Iceland to have surgery under false pretences (Tilley et al., 2012). Hreinsdóttir found out at the age of 27 how she had been deceived and has since made public interviews about her experience and feelings and, with support, has published articles (Stefánsdóttir and Hreinsdóttir, 2013). Those who were tricked into the operation, particularly, felt a strong feeling of shame. They came to realise that the siting of their abdominal scar was not correct for an appendicectomy. In some cases a normal appendix was actually removed at the time of the sterilisation. Other individuals were told they were being admitted for tonsillectomy.

\section{Coercion and undue influence}

Coercion or undue influence can be considered as part of the 'system' or brought to bear by individuals. In institutions, coercion was often an integral part of the system. Those with ID were identified in the community and 'fed' into the machinery of the institutions. The Superintendents were powerful people and could present a case to the Eugenics Board in a way that made endorsement of sterilisation all but certain. 
Third parties exerting undue influence or coercing those with ID could be professionals or relatives. Pressure has often been applied by the medical profession and by social workers (Carey, 1998; Kaelber, 2011; Roets et al., 2006; Stefánsdóttir, 2014). Ruth Cox, an 18-year old black unmarried mother was coerced in 1965 by her mother's social worker to consent to sterilisation under North Carolina's eugenic law; a threat of withdrawal of welfare payments was made (Schoen, 2001). Although Cox had never been formally assessed, the surgeon who performed a bilateral salpingectomy described her as a "mentally-deficient Negro girl"; later in life she became an auxiliary nurse (Trombley, 1988). One male social worker in North Carolina is reported to have 'arranged' for all the women on his caseload to be sterilised (Schoen, 2001).

Even up to the present time, parents or guardians tend to make applications for sterilisation that are based on factors other than solely the human rights of the individual concerned. For example, Pauline's mother requested and obtained a sterilisation for her daughter in order to free herself from the fear of pregnancy as Pauline "would just go off with anyone" (Tilley et al., 2012). Regrettably, mothers and sisters have been recorded as colluding with coercion into the sterilisation of their next of kin (Stefánsdóttir, 2014).

\section{Resisting sterilisation through empowerment}

There is a moving account of how, with support, a Belgian woman called 'Marie' with ID managed to resist having a sterilisation foisted on her by health and social 'care' services in 2002 (Roets et al., 2006). She was being pressurised by health professionals who were also feeding her misinformation. The detailed qualitative analysis in this case illustrates how far 
society has come in empowering those with mental impairment. It also shows how, even in the $21^{\text {st }}$-century, professional attitudes toward involuntary sterilisation can be outdated.

\section{Is a best interests framework good enough?}

'Best interests' as a framework for making decisions about sterilisation applications is now considered by some scholars and human rights advocates to be flawed. The concept was adapted from family law applicable to children; in fact, dealing with the difficulties associated with ID and incapacity is far more complex than children's cases. As well as being paternalistic, the concept has no hierarchy of values which those making the final decision can weigh (Brady, 2001).

Best interests often have little to do with the rights of those with ID and more to do with social factors, such as avoiding inconvenience for carers, the lack of adequate measures to protect against sexual abuse and exploitation and the lack of adequate and appropriate services to support people with ID in their decision to become parents (Anonymous, 2011).

\section{More recent changes in legislation and case law: Canada and Australia} In countries with and without statutes governing sterilisation, case law has developed over time.

\section{Canada}


A landmark case was heard in the Canadian Supreme Court in 1986. The mother of a woman with ID known as 'Eve' applied for her daughter to be sterilised. The Court ruled that such an invasive procedure which had no therapeutic purpose could not be justified (Dickens, 1987). A procedure that renders a woman sterile in a case in which no medical condition such as fibroids or heavy menstrual bleeding is being treated is referred to as non-therapeutic sterilisation.

\section{Australia}

Australia did not enact legislation to make involuntary sterilisation lawful, but such procedures did take place in that country and public concern led to a Senate Inquiry in 2013 (Parker, 2013). Best known is the 1992 case in the Northern Territory of 14-year old 'Marion', whose parents applied for her to have a hysterectomy and oophorectomy. At appeal in the High Court of Australia, the judges ruled in the same way as in 'Eve' that parents could not make such a non-therapeutic decision (Parker, 2013). However, it is apparent that more than a thousand sterilisations (of which about 200 were hysterectomies) on adolescent girls with ID took place outside the Australian court system during the 1990s. In many of these cases, narrow evidence from lay people as well as medical experts was used to justify sterilisation, often claiming the procedure to be in the best interests of the individual concerned. Particularly abhorrent were the cases of hysterectomy on girls ranging in age down to 10 years old, done mainly on the basis of inconvenient menstrual periods or even, in prepubescent girls, in anticipation of their menarche (Brady, 2001; Brady et al., 2001). The Senate Inquiry came out with robust recommendations about banning sterilisation of disabled people without their consent if they had already achieved or might in the future reach capacity to consent (Community Affairs References Committee, 2013). 
More recent policy approaches in three countries: United Kingdom, Germany and France

\section{United Kingdom}

Like Australia, the UK has never had legislation governing involuntary sterilisation. The Courts have played an active rôle in ensuring that any coercive practices are curtailed. More recently there has been tighter control in response to the increasing emphasis on human rights considerations. Case law on sterilisation of those with ID in the UK has been built up over the last 40 years. Following referral to the Official Solicitor of England and Wales in the 1990s, and approval in the High Court, 30 women were sterilised and seven had hysterectomies (Stansfield et al., 2007). The applications were reported to have been driven by a mixture of a fear of the risks associated with the woman in question being of childbearing capacity, parental attitudes about contraception, seeking a permanent solution to unbridled fertility and concern about who will care for a child born to the woman.

The advent of the Mental Capacity Act 2005, which applies in England and Wales, has had a substantial impact on how such cases are handled (Laurie et al., 2016). They are now heard in the Court of Protection (Rowlands, 2011). All cases of non-therapeutic sterilisation need to have a court hearing. Applications are made by the health and social services authorities that are responsible for the care of the individual concerned. The Court will act in what it deems are the best interests of those who lack mental capacity. A balance is struck between the person's protection and empowerment. The Court examines social as well as medical aspects of the case. Each decision will be fact-specific; in other words, decisions made in 
other such cases do not set precedents. With the advent of long-acting reversible contraception, sterilisation is often an unnecessarily invasive and restrictive option. Nevertheless, a few cases of sterilisation of both women (Anonymous., 2015) and men (English, 2013) do get approved by this Court after detailed consideration of the particulars of the case.

The Mental Capacity Act 2005 has, however, been criticised because of its lack of human rights considerations; also because its best interests approach is paternalistic (Dimopoulos, 2010). The Mental Capacity Act gives no right of the incapacitated to be heard; their voice is consulted only if it is practicable to do so.

\section{Germany}

Since the reunification of Germany in 1992, there has been strong protection and support for the disabled (Dimopoulos, 2010). Disabled people are entitled by law to have a carer appointed who acts as their legal representative. The carer must take into account the wishes of the disabled person; carers are under the constant control and supervision of the guardianship court.

Specifically in relation to sterilisation, a person (even an individual without capacity) has an absolute right to veto being sterilised (Dimopoulos, 2010). Even for those requesting sterilisation of their own free will, conditions that must be met are a grave/imminent risk of pregnancy, that such a pregnancy would endanger the life of that person and that pregnancy cannot be prevented by less restrictive means. There is a mandatory 'cooling-off' period of 
two weeks. No physical force is permitted when carrying out a sterilisation procedure. Since 1997 there is a sparse case law; very few cases have been approved.

\section{France}

In France, until the law of 4 July 2001 allowed sterilisation as permanent contraception, it was a criminal offence to perform such a procedure unless it was done in order to preserve health or life - for so-called therapeutic reasons (Latham, 2002). Now, under the 2001 law, non-therapeutic sterilisation of mentally-disabled adults is permitted in cases in which reversible contraceptive methods are strongly advised against and the impossibility of implementing them has been certified; the person's consent is always required and an individual's refusal cannot be over-ruled.

\section{Responses of international bodies}

Human rights bodies have recognised that sterilisation of people with ID without their consent constitutes discrimination, a form of violence and torture, or other cruel, inhuman or degrading treatment (WHO, 2014). Involuntary sterilisation involves a serious invasion of physical integrity with a resulting grave impairment of human dignity (Holness, 2013). The World Health Organization recommends that substitute decision-making, where third parties can make decisions on behalf of an individual, should be replaced by supported decisionmaking laws and policies (D’Espallier, 2014).

The 2006 United Nations Convention on the Rights of Persons with Disabilities (CRPD) is based on the social model of disability (UN Division for Social Policy and Development, 
2006). It includes the provision that "persons with disabilities, including children, retain their fertility on an equal basis with others." This entails keeping one's reproductive capacities or alternatively the opportunity to freely choose to have one's reproductive capacities limited.

In 2011, five women with ID took their case to the European Court of Human Rights (ECtHR) (Gauer and others v France 2012). They claimed they had all been sterilised unlawfully in the city of Sens between 1995 and 1998. The case had begun 11 years previously but had been unsuccessful in the French courts. Unfortunately, the case was ruled as out of time and not heard. No other cases have been through the ECtHR. The silence of the ECtHR on this matter contrasts with the clarity of the CRPD (D'Espallier, 2014).

\section{Modern approaches to judging sterilisation requests}

There remain issues in relation to sterilisation requests for those with ID that are problematic. It has been clear for some time that therapeutic sterilisations are legal in most jurisdictions. But is a sterilisation for the purposes of 'menstrual hygiene' a valid ground to invoke under this heading? It would seem that there is still quite a widespread practice of sterilising women with ID on this basis. For instance, in New Zealand the practice has been shown to have still occurred in the 1990s; some of the girls concerned were aged less than 15 years (Hamilton, 2012). The practice was also widespread in Australia and was one of the concerns of the Senate Inquiry (Brady et al., 2001; Community Affairs References Committee, 2013). 
Key issues that have been identified in relation to those with ID and consent include their general disempowerment, communication difficulties and their tendency to acquiesce to a proposal (Howard and Hendy, 2004). As mentioned above, there is also the flagrant abuse under former laws including overt coercion and either a lack of information-giving or provision of false information. There is also more subtle pressure from professionals or relatives.

There are examples of sincere efforts to produce guidance on how to enable decisions to be made. Even in the last 20 years it has been advised that emphasis should be placed on making a thorough assessment of a person's parenting ability (Denekens et al., 1999).

Some relevant points about how a decision should be approached, before even contemplating a court hearing, have been drawn up. Sterilisation should only be considered for those with ID who are physically capable of procreation, who are likely to engage in sexual activity and who are exposed to a real risk of pregnancy (Howard and Hendy, 2004). For example, men with Down syndrome generally have negligible fertility - only three pregnancies have ever been reported (Pradhan et al., 2006). Sterilisation would not appear to be justifiable on the following grounds (Howard and Hendy, 2004):

- prevention of transmission of ID to any progeny

- risk of the woman being sexually abused (rather, she needs protection from abuse)

- risk of the woman being traumatised by the experience of pregnancy and childbirth

- $\quad$ perceived lack of parenting ability 
Valid grounds would be confined to (Dimopoulos, 2010):

- avoidance of grave and imminent harm from conception/pregnancy

- sexually-active people

- those in whom a less-restrictive option (reversible contraception) is not suitable

- sexual training has been undergone but has failed

\section{Long-term effects of non-consensual sterilisation on individuals}

Early research into this subject was superficial and those who expressed regret were not given the opportunity to expand on the negative impact the sterilisation had had on them. From limited short-term follow-up of some of the cases at the Essondale Provincial Mental Hospital in British Columbia, Canada, sterilisation was considered by the authorities as a 'success' in most cases. The fact that many individuals had been discharged from hospital and were living in the community was thought to be suggestive of a positive outcome (van Heeswijk, 1994).

More recently, some detailed narratives have been obtained from lengthy repeated conversations with those who were sterilised. The Alberta Living Archive Project contains several of these. There is also some scholarly work from Iceland. An example of this is Ebba Hreinsdóttir in Iceland, already mentioned (Stefánsdóttir and Hreinsdóttir, 2013). Another is Leilani Muir in Canada (see her case history above) who was particularly vociferous about the effect being sterilised had had on her. Sadness, anger and grief are the prime emotions 
which are common to those who were sterilised without their knowledge or against their will. As well, there is a pervasive sense of shame. The loss of fertility and inability to form a family have profound and permanent stigmatising effects on individuals themselves and on their relationships with others.

More is known about what happened to people with ID who were residents in institutions than those living in the community with their families (Tilley et al., 2012). The first report of the subjects' views on having been sterilised by deception were published in 1962; unsurprisingly a majority were aggrieved (Sabagh and Edgerton, 1962). There are a few cases of non-consensual sterilisation in the UK that have been identified from oral history evidence (Tilley et al., 2012). In the early 1970s 'Anita' was taken into hospital at the age of 14 purportedly to have an appendicectomy (Tilley et al., 2012) in a similar fashion to the case of Hreinsdóttir already described. "I was duped" emerged as one of the themes in qualitative analysis of life history interviews of those who had gone through such experiences (Stefánsdóttir, 2014).

\section{Reparations}

Survivors of historic injustices deserve to have amends made for the wrongs done to them (Braun et al., 2014). Four aspects to reparations for injustices have been postulated: recognition that they occurred, acknowledgement by governments, apologies (which are symbolic) and financial redress (which is material) (Gerodetti, 2016). In order that an apology functions fully it needs to take the shame from the person who suffered and place it on the government (even though the action was carried out by a predecessor administration). 
Public apologies were forthcoming in the North American jurisdictions of Alberta, Virginia, Oregon, North Carolina, South Carolina and California. However, these were all worded in general terms and did not single out those with ID as a specific group that should receive an apology. Rarely, there are historic signs erected locally to acknowledge the wrong that was done (see case history of Carrie Buck and photograph). These tend to apologise generally about eugenic policies rather than accepting that those with diagnosed/supposed/purported ID were particularly targeted for sterilisation.

[Insert Box about Carrie Buck about here]

So far, only Alberta, North Carolina and Virginia have agreed to provide financial redress. Some of those sterilised sued their governments individually, for example Leilani Muir in Canada. In some jurisdictions, such as Alberta, an individual award of damages opened the floodgates and was followed by hundreds of other successful claims. Elsewhere, for example in Sweden, a government inquiry led to mass cash compensation awards.

\section{Discussion}

Over the last few decades, previously unknown sterilisation abuses have been uncovered. Practices have been exposed that countries would rather forget, and which align them more closely with practices in Nazi Germany than they would like to admit. Non-consensual sterilisation is a shocking historical abuse that can be compared with sexual abuse in its profound damaging effects on survivors. One of the distressing elements of it is that such sterilisation was entirely legal in many jurisdictions over a period of some years. People with 
ID are among the most vulnerable in society. The eugenics movement viewed them with disgust; negative eugenics decreed that they be prevented from 'breeding'. In certain countries in which there was not much opposition, eugenicists persuaded politicians to vote for compulsory sterilisation laws. In these jurisdictions, generally where there were likeminded eugenicists and health professionals working together, sterilisations could be performed on a grand scale. Eugenics Boards often over-stepped their statutory powers. Some enthusiastic physicians and social workers 'fed' candidates into the system using coercive practices. Consent was either considered not to be needed or was compromised. Third party consent was a convenient way of getting round incapacity; relatives of those with ID either coerced the individual or were themselves coerced by health professionals.

Residents of institutions were extremely susceptible and suggestible; they were easy prey to the Superintendents of the institutions. Tenuous personal and family information was used to support applications for sterilisation. Overt deception was common.

Although it may be considered invidious to make comparisons with sexual abuse, it is clear that being compelled to have an operation that permanently forecloses the ability to procreate is likely to have devastating psychological effects on individuals. We now have concrete evidence of such effects. Although it may seem a trivial redress to those affected, the opportunity to talk about the experience openly over time is beneficial; for a few, 'going public' is their way of dealing with the situation. Reparations are also supportive to those who have been through non-consensual sterilisation. 
In terms of prevention, sterilisation laws have been repealed and nearly all countries are signed up to human rights protections to some degree. Courts are now adopting approaches to reproductive rights that respect people's dignity and bodily autonomy. Moving from a medical model of disability to a social model is helpful. It is generally considered that cases without a distinct therapeutic component should go through the courts. In the courts, criteria that would justify sterilisation have been narrowed and there is a reluctance to bow to pressure to make rapid decisions. Individuals are given plenty of support and as far as possible are involved in decision-making. It seems, however, that professional attitudes have not always caught up with shifts in legal and ethical thinking and social policy.

We have come from a dark history to a more enlightened approach. Lessons appear to have been learned along the way in most countries. We should salute the courage of those survivors who have publicised their stories. 


\section{Case histories}

[Each in a Box with borders]

Leilani Muir (1944 - 2016)

A precondition for the admission of Leilani Muir to the Red Deer Provincial Training School in Alberta, Canada, at the age of 10 was a signature from her mother on papers for her compulsory sterilisation. Muir was sterilised in 1959. She had been institutionalised on flimsy grounds and was not discharged until the age of 20. IQ testing placed her at the lower end of the normal range. Later in life she underwent investigations for infertility, which revealed that the full length of both her tubes was absent due to salpingectomy.

Muir sued the Alberta government in 1995 and received Can\$740,780 in damages in 1996 (Queen's Bench of Alberta, 1996). Roughly half of the damages awarded for pain and suffering was for wrongful detention in an institution; the other half was for wrongful sterilisation. The judge awarded the maximum amount allowed in law because of the "catastrophic impact on Ms Muir. It changed, warped and haunted her life". Hundreds of other victims in that province received payouts; about 500 claimants settled for a total of Can\$48 million in 1998. The following year, Alberta agreed to a Can\$82 million compensation package for another 247 victims of forced sterilisation (Hancock, 1999). The Premier of the Province expressed his profound regret in 1999 (Hancock, 1999). 
A documentary was made about Muir's life (Whiting, 1996) and she wrote an autobiography (Muir, 2014). She has related to the Living Archives on Eugenics in Western Canada Project (SSHRCC, 2017) how sterilisation "ruined her life". She continued to speak about her life story at international conferences for some years.

Ingrid Van Butsel (1957 - ?)

In Belgium, Ingrid Van Butsel had spent the early part of her life in orphanages and state housing for young women who have no family, no money and few skills. She was classified as having mild ID although any deficit was actually due to her poor education. She was allowed to marry, in 1985, only after the institution where she lived had pressured her into being sterilised beforehand, on the grounds that she was unfit to raise children. If she had not acquiesced, she would have been sent to a psychiatric hospital. Van Butsel could not challenge the decision due to her vulnerability. She became depressed, gained considerable weight and suffered from poor health. Her letters to the Belgian King and Prime Minister went unanswered. In 1996, she filed a complaint with the 'Orde van Geneesheren' (Medical Council), that dismissed it on ludicrous and blatantly partial grounds. In 1998, Van Butsel sued the gynaecologist who had sterilised her. After a trial that had lasted for more than four years, she (!) was ordered to pay compensation of $€ 3,718$ to the gynaecologist and to reimburse the costs of the court procedure because, in the magistrate's view, she had "cast a bad light over the practitioner's reputation, manifestly without any hope of a successful outcome" (Vanhaelen and Van Butsel, 2003). 
The case illustrates the collusion between those in positions of power, some of whom were involved in the compulsory sterilisation of a person who was neither mentally- nor physically disabled, and others who endorsed this inhumane intervention (Wielaard, 1997).

\section{Maria Nordin (dates not known)}

Maria Nordin lived in the Swedish town of Gävle. She was viewed as educationally 'inferior' by her teachers at the reform school for girls; her problem, however, was not any lack of intellect but that her shortsightedness (uncorrected, as she had no glasses) prevented her from reading the blackboard (Murphy, 1997). She was called into the school office at the age of 17 to sign sterilisation papers. Other reasons from her family background put forward to support the application for her sterilisation were alcoholism, promiscuity and mental illness. Nordin stated that the threat was made that she would stay locked up for ever if she did not cooperate. In the end she relented and submitted herself to the operation. Oophorectomy was carried out at Bollnäs hospital in 1943. Interviewed in 1997 at the age of 72 she recalled "I hid in the basement bathroom crying all by myself. I was thinking of killing myself, and I have been thinking of it ever since. But I never wanted to give them the satisfaction of getting rid of me. I tried to let my hatred go, to melt it down. But it isn't possible for me".

In the 1960s, Nordin and her husband confronted the physician and the headmistress with the false diagnosis that was used to authorise her sterilisation. "They are lies - feebleminded and all those other words they said about me - lies that ruined me". In 1966 Nordin went 
public with her story. "The biggest relief is that people finally understand that I am the one telling the truth about me".

Nordin demanded compensation from the Swedish government in 1996; her claim was rejected intially. Later, after prominent newspaper headlines about her story, an ex-gratia payment was made to her.

Carrie Buck (1906 - 1983)

Carrie Elizabeth Buck was a resident of the Virginia State Colony for Epileptics and Feebleminded, the largest such institution in the USA when it opened in 1910 (Historical Exhibits: Claude Moore Health Sciences Library, 2007a). Dr John Bell carried out a sterilisation procedure on her in 1927 when she was aged 20. She married in 1932 and remarried on the death of her first husband, her second marriage lasting until her death in 1983. She expressed regret for the rest of her life that she could not have children with either spouse.

The notorious court decision in Buck v Bell would later be seen to have been ill-founded, even considering the climate of the day (Trombley, 1988). Carrie Buck's mother had mild ID only. Carrie herself had normal intellect but had been institutionalised on the basis of the 'promiscuity' associated with becoming a rape victim at the age of 17. Carrie's daughter Vivian, conceived as a consequence of the rape, performed well at school before she died of 
measles at the age of 8. In 1994 a television documentary was made about Carrie (Coles, 1994).

A posthumous apology to Carrie was made by the Virginia State Governor in 2002 (Historical Exhibits: Claude Moore Health Sciences Library, 2007b). Also in 2002, a historical marker was erected to commemorate those sterilised under the Virginia sterilisation law (Historical Exhibits: Claude Moore Health Sciences Library, 2007b) - see photograph. 


\section{Declaration of conflicting interests}

The authors declare no potential conflicts of interest with respect to the research, authorship and/or publication of this article.

\section{Funding}

The authors received no financial support for the research, authorship and/or publication of this article. 


\section{Photograph}

Caption: Historical marker in Charlottesville, Virginia, about Buck v Bell

Courtesy of Historical Collections \& Services, Claude Moore Health Sciences Library, University of Virginia. 


\section{References}

Anonymous. (2000) Steriliseringsfrågan i Sverige 1935-1975: historisk belysning, kartläggning, intervjuer [The sterilisation issue in Sweden 1935-1975: historical illumination, mapping and interviews]. Stockholm: Regeringskansliet.

Anonymous. (2011) Sterilization of women and girls with disabilities. Available at:

https://www.hrw.org/news/2011/11/10/sterilization-women-and-girls-disabilities

Anonymous. (2015) Case commentaries: sterilisation. Available at:

http://www.courtofprotectionhub.uk/cases/the-mental-health-trustthe-acute-trustthe-council-v-dd-and-bc-reported-as-re-dd-no-4-sterilisation-2015-ewcop-4

Benjamin LT. (2009) The birth of American intelligence testing. Monitor on Psychology 40: 20.

Brady SM. (2001) Sterilization of girls and women with intellectual disabilities. Violence Against Women 7: 432-461.

Brady SM, Britton J and Grover S. (2001) The sterilisation of girls and young women in Australia: issues and progress. Sydney: Australian Human Rights Commission.

Braun K, Herrmann SL and Brekke OA. (2014) Sterilization policies, moral rehabilitation and the politics of amends. Critical Policy Studies 8: 203-226.

Carey AC. (1998) Gender and compulsory sterilization programs in America: 1907-1950. Journal of Historical Sociology 11: 74-105.

Coles JD. (1994) Against her will: the Carrie Buck story. Originally aired on 5 October 1994 on Lifetime cable network.

Community Affairs References Committee. (2013) Involuntary or coerced sterilisation of people with disabilities in Australia, Canberra: Commonwealth of Australia. 
D'Espallier A. (2014) Cutting the ties: sterilisation of persons with disabilities. New perspectives after the introduction of the CRPD. IXth World Congress of Constitutional Law. Oslo.

Denekens JPM, Nys H and Stuer H. (1999) Sterilisation of incompetent mentally handicapped persons: a model for decision making. Journal of Medical Ethics 25: 237-241.

Dickens B. (1987) No contraceptive sterilization of the mentally retarded: the dawn of "Eve". Canadian Medical Association Journal 137: 65-67.

Dimopoulos A. (2010) Issues in human rights protection of intellectually disabled persons, Farnham: Ashgate.

Drouard A. (1999) Concerning eugenics in Scandinavia. An evaluation of recent research. Population: an English selection 11: 261-270.

Editorial. (1910) The care of the feeble-minded. Spectator.

English R. (2013) High Court upholds autonomy over fatherhood for learning disabled man. Available at: https://ukhumanrightsblog.com/2013/08/20/high-court-upholdsautonomy-over-fatherhood-for-learning-disabled-man/

Gerodetti N. (2016) Whose reparation claims count? Gender, history and (in)justice. Australian Feminist Legal Journal 42: 97-118.

Hamilton C. (2012) Sterilisation of intellectually disabled people in New Zealand - still on the agenda? Kōtuitui: New Zealand Journal of Social Sciences Online 7: 61-71.

Hancock D. (1999) Stratton Agreement concludes sterilization negotiations. Edmonton: Government of Alberta.

Historical Exhibits: Claude Moore Health Sciences Library. (2007a) Buck v. Bell: the Test Case for Virginia's Eugenical Sterilization Act. Available at: http://exhibits.hsl.virginia.edu/eugenics/3-buckvbell/ 
Historical Exhibits: Claude Moore Health Sciences Library. (2007b) Carrie Buck revisited and Virginia's expression of regret for eugenics. Available at:

\section{http://exhibits.hsl.virginia.edu/eugenics/5-epilogue/}

Holness W. (2013) Informed consent for sterilisation of women and girls with disabilities in the light of the Convention on the Rights of Persons with Disabilities. Agenda 98: 3554.

Howard R and Hendy S. (2004) The sterilisation of women with learning disabilities - some points for consideration. British Journal of Developmental Disabilities 50: 133-141.

Jütte R. (2008) Contraception: a history, Cambridge: Polity Press.

Kaelber L. (2011) Eugenics: compulsory sterilization in 50 American States. Available at: http://www.uvm.edu/ /kaelber/eugenics/

Latham M. (2002) Regulating reproduction: a century of conflict in Britain and France, Manchester: Manchester University Press.

Laurie GT, Harmon SHE and Porter G. (2016) Law \& Medical Ethics, Oxford: Oxford University Press.

Lynöe N. (2007) Race enhancement through sterilisation: Swedish experiences. International Journal of Mental Health 36: 17-25.

Muir L. (2014) A whisper past: childless after eugenic sterilization in Alberta, Victoria, British Columbia: FriesenPress.

Murphy DE. (1997) A victim of Sweden's pursuit of perfection. Los Angeles Times.

Park DC and Radford JP. (1998) From the case files: reconstructing a history of involuntary sterilisation. Disability and Society 13: 317-342.

Parker M. (2013) "Forced sterilisation": clarifying and challenging intuitions and models. Journal of Law and Medicine 20: 512-527. 
Pradhan M, Dalal A, Khan F, et al. (2006) Fertility in men with Down syndrome: a case report. Fertility \& Sterility 86: 1765.e1761-e1763.

Proctor RN. (1988) Racial hygiene: medicine under the Nazis, Cambridge, Massachusetts: Harvard University Press.

Queen's Bench of Alberta. (1996) Muir v Alberta, 1996 CanLII 7287 (AB QB).

Ramsay S. (2000) Enforced sterilisations in Sweden confirmed. The Lancet 355: 1252.

Roets G, Adams M and van Hove G. (2006) Challenging the monologue about silent sterilization: implications for self-advocacy. British Journal of Learning Disability 34: 167-174.

Rowlands S. (2011) Learning disability and contraceptive decision making. Journal of Family Planning \& Reproductive Health Care 37: 173-178.

Sabagh G and Edgerton RB. (1962) Sterilized mental defectives look at eugenic sterilization. Eugenics Quarterly 9: 213-222.

Schoen J. (2001) Between choices and coercion: women and the politics of sterilization in North Carolina, 1929-1975. Journal of Women's History 13: 132-156.

Servais L, Leach R, Jacques D, et al. (2004) Sterilisation of intellectually disabled women. European Psychiatry 19: 428-432.

Social History of Learning Disability Research Group. (2012) Timeline of learning disability history. Available at: http://www.open.ac.uk/health-and-socialcare/research/shld/timeline-learning-disability-history.

SSHRCC. (2017) Eugenics Archive. Ottawa: Social Sciences and Humanities Research Council of Canada. 
Stansfield AJ, Holland AJ and Clare ICH. (2007) The sterilisation of people with intellectual disabilities in England and Wales during the period 1988 to 1999. Journal of Intellectual Disability Research 51: 569-579.

Stefánsdóttir GV. (2014) Sterilisation and women with intellectual disability in Iceland. Journal of Intellectual \& Developmental Disability 39: 188-197.

Stefánsdóttir GV and Hreinsdóttir EE. (2013) Sterilization, intellectual disability, and some ethical and methodological challenges: It shouldn't be a secret. Ethics \& Social Welfare 7: 302-308.

Tilley E, Earle S, Walmsley J, et al. (2012) 'The silence is roaring': sterilization, reproductive rights and women with intellectual disabilities. Disability and Society 27: 413-426.

Trombley S. (1988) The right to reproduce: a history of coercive sterilization, London: Weidenfeld \& Nicolson.

UN Division for Social Policy and Development. (2006) Convention on the Rights of Persons with Disabilities. Available at:

www.un.org/development/desa/disabilities/convention-on-the-rights-of-personswith-disabilities.html

van Heeswijk G. (1994) An Act respecting sexual sterilization: reasons for enacting and repealing the Act. MA thesis. Vancouver: University of British Columbia.

Vanhaelen J and Van Butsel I. (2003) Gedwongen sterilisatie [Forced sterilisation]. Available at: http://www.sarahbeweging.net/getuigenissen/ingrid.html

Watson J. (2016) Assumptions of decision-making capacity: the role supporter attitudes play in the realisation of Article 12 for people with severe or profound intellectual disability. Laws 5: 6.

Whiting G. (1996) The sterilization of Leilani Muir. National Film Board of Canada. 
WHO. (2014) Eliminating forced, coercive and otherwise involuntary sterilization, Geneva: World Health Organization.

Wielaard R. (1997) Forced sterilization exposed in Sweden, Belgium. New York: Associated Press. 